\title{
sciendo
}

RESEARCH PAPERS FACULTY OF MATERIALS

SCIENCE AND TECHNOLOGY IN TRNAVA

SLOVAK UNIVERSITY OF TECHNOLOGY

IN BRATISLAVA

2018, Volume 26, Number 43

DOI 10.2478/rput-2018-0030

\section{STRUCTURAL ANALYSIS OF SUPERCONDUCTORS AT MTF:}

\section{A REVIEW}

\section{Michal SKARBA ${ }^{1}$, Marcela PEKARČÍKOVÁ ${ }^{2}$, Pavol KONOPKA $^{3}$, Jozef MIŠÍK ${ }^{2}$, Eva CUNINKOVÁ ${ }^{2}$}

${ }^{1}$ SLOVAK UNIVERSITY OF TECHNOLOGY IN BRATISLAVA, FACULTY OF MATERIALS SCIENCE AND TECHNOLOGY IN TRNAVA, ADVANCED TECHNOLOGIES RESEARCH INSTITUTE, ULICA JÁNA BOTTU 2781/25, 91724 TRNAVA, SLOVAK REPUBLIC e-mail: michal.skarba@stuba.sk

${ }^{2}$ SLOVAK UNIVERSITY OF TECHNOLOGY IN BRATISLAVA, FACULTY OF MATERIALS SCIENCE AND TECHNOLOGY IN TRNAVA, INSTITUTE OF MATERIALS SCIENCE,

UliCA JÁNA BotTu 2781/25, 91724 TRNAVA, SLOVAK REPUBLIC

e-mail:marcela.pekarcikova@stuba.sk,jozef.misik@stuba.sk, eva.michalcova@stuba.sk

${ }^{3}$ KoMENSKÉHO 4530/6, PieŠŤANY, 92101, SLOVAKIA

e-mail: pavol.konopka@gmail.com

Received: 12.11.2018, Accepted: 10.01.2018, Published: 29.01.2019

\begin{abstract}
The activities of the young STU MTF research team focused on the material properties of superconductors were reviewed for the first time. We performed structural analyses on multiple types of superconducting tapes in order to get deeper insight into the correlation between their structure and electromagnetic properties, both experimentally and by modelling. We also addressed the joining of tapes by lead-free solders.
\end{abstract}

\section{Key words}

Superconductivity, coated conductors, (RE)BCO, structural analysis, outgrowths, pinning, mechanical loading, soldering, TORT, FEM, soldered overlap joint

\section{INTRODUCTION}

Superconductors are the materials, which can conduct electric current without resistance, if certain conditions are met. Since the discovery of this extraordinary ability in 1911, it has been found that dozens of chemical elements and thousands of superconducting alloys and chemical compounds have superconducting properties and could be used in a form of bulk, wires or thin layers. In terms of practical use, one of the most perspective superconducting 
materials seems to be the high-temperature superconductors (HTS) as a thin ceramic layer, with assembly of auxiliary layers - the so called coated conductors. Unfortunately, many advantages of the coated conductors are compensated by strong dependence of their electromagnetic properties on the material structure. Thus, the primary goal of our research team was devoted to finding correlations between structural phenomena in superconductors and their electromagnetic performance.

In the first stage of our research activities, we tried to get insight into the structure of superconducting layer as received from the producer, after the metallic overlayers were removed by chemical etching (1-4). During cabling, handling, joining and operation, the tapes are expected to experience mechanical loads, which may significantly modify their structure, and hence alter the electromagnetic properties. Thus, in the second stage, we spent efforts to understand the changes in the structure after the tapes were mechanical loaded $(5,6)$. For some applications, longer lengths of tapes are required than it is feasible to prepare; there is thus necessity to improve joining techniques with the goal to minimize degradation effects of the joining on superconductor $(7,8)$.

\section{MATERIALS AND METHODOLOGY OF EXPERIMENTS}

Superconducting tapes of various producers (SuperPower Inc., Fujikura Ltd., SuperOx and SuNam Co.) and different widths (typically 4 or $12 \mathrm{~mm}$ ), various architectures of layers and their thicknesses were used. A typical cross-section of the investigated tape is sketched in Fig. 1a.

For imaging, we used scanning electron microscopy (SEM), transmission electron microscopy (TEM) and laser scanning confocal microscopy (LSCM). Chemical composition was measured by energy dispersive X-ray spectroscopy (EDX). Detailed structural information was gained from X-ray diffraction (XRD) and electron backscatter diffraction (EBSD). Universal testing machine of UMZ-3K was used for mechanical tests of tapes, coupled with a home-made Nyilas-type double extensometer configuration. Preparation of some superconducting layers was performed by pulsed laser deposition (PLD), metal-organic chemical vapour deposition (MOCVD) and reactive co-evaporation (RCE) methods. For modelling, the ANSYS R18.1 Academic Workbench software was employed.

(a)

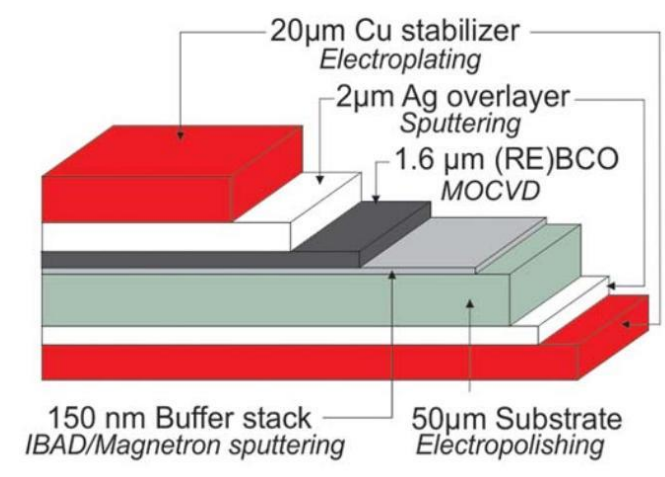

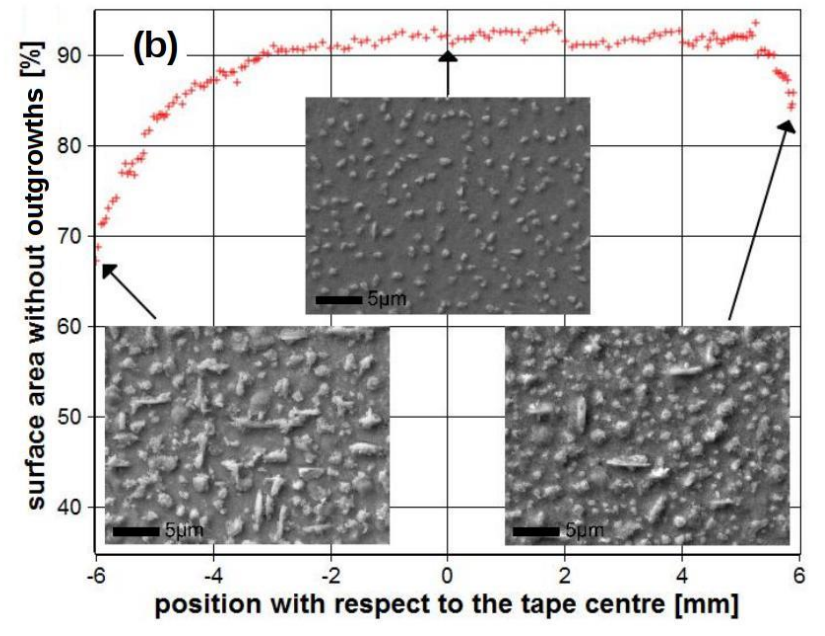

Fig. 1 Properties of superconducting tapes. (a) Scheme of a typical (RE)BCO ( $=(R E) B a_{2} C u_{3} \mathrm{O}_{7-\delta}$, $R E=$ rare earth element, typically $Y$ or $G d)$ HTS tape (4). This particular tape is SuperPower SCS12050-AP. (b) Top view of (RE)BCO layer by SEM (1). 


\section{RESULTS AND DISCUSSION}

\section{Structure of superconducting thin layer before application of a mechanical load}

Various structural features affect the performance of a superconductor, such as precipitates, stacking faults, outgrowths and pinning centres (4); we will further discuss the latter two phenomena.

In the top view of (RE)BCO layer by SEM (Fig. 1b), we found that the distribution of outgrowths was spatially non-uniform, as can be observed in the dependence of non-outgrowth area ratio across the tape width (1). Using LSCM, we determined the surface area roughness to the range from 54 to $79 \mathrm{~nm}$ (3). The nature of outgrowths was also examined by SEM in crosssection (Fig. 2a) (2). Complementary EDX analysis showed spatial variation in concentration of $\mathrm{Cu}, \mathrm{O}, \mathrm{Y}$ and $\mathrm{Ba}$ (Fig. 2b-e); thus our hypothesis is that the outgrowths may be composed of $\mathrm{CuO}, \mathrm{Y}_{2} \mathrm{O}_{3}, \mathrm{CuYO}_{2}$ or $\mathrm{Y}_{2} \mathrm{Cu}_{2} \mathrm{O}_{5}$. As the latter phases are non-superconducting, their distribution seems to significantly influence the electromagnetic properties of tapes. Measurements of critical current density (not shown in Figures) exhibited strong correlation with the results in Fig. 1b.
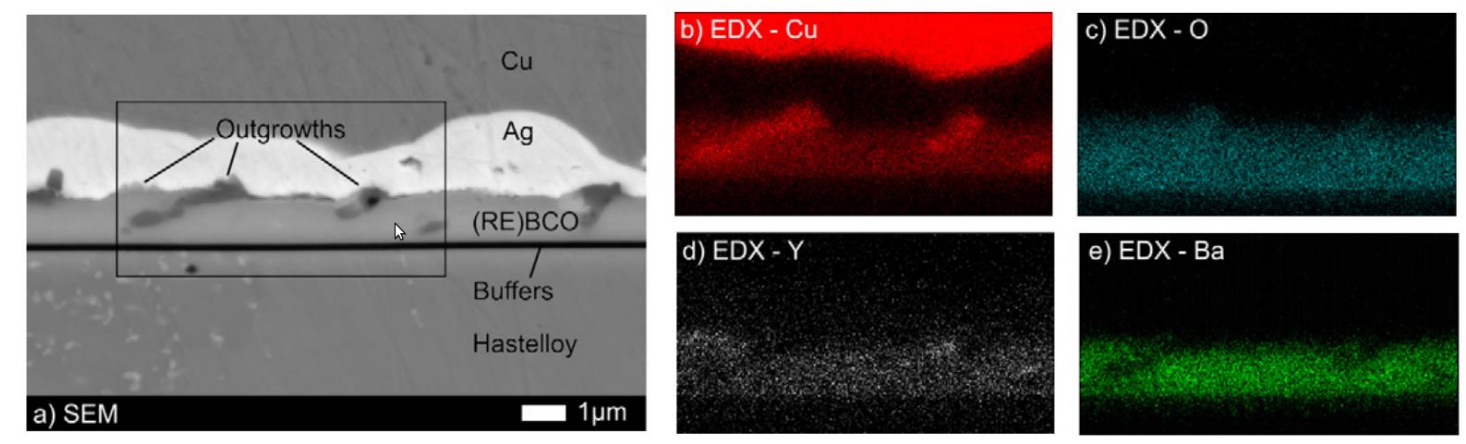

Fig. 2 Cross-section of the superconducting tape close to the tape edge (2): (a) SEM micrograph of rounded outgrowths, $(b)-(e)$ elemental chemical analysis (EDX mapping in area marked in Fig. 2a), where higher colour intensity means higher element concentration

To further clarify the effects of outgrowths, SEM images of cross-section of SuperPower SCS4050 tape perpendicular to long-length were taken, supported by the EBSD crystal orientation analysis (Fig. 3a, (3)). In Fig. 3a, an example of a needle-like shaped outgrowth with a-axis orientation is marked with red circle (also shown in Figs. 3d and 3e); on other places, rounded outgrowths were found (Figs. $3 b$ and 3c; see also Fig. 2). Both types of outgrowths had randomly oriented grains (Fig. 3a top), while the outgrowth-free regions (Fig. 3a bottom) indicate uniform orientation, which is an essential condition for the flow of superconducting current. Strongly textured structure of HTS layer in [001] direction was also confirmed by XRD analysis (9). 

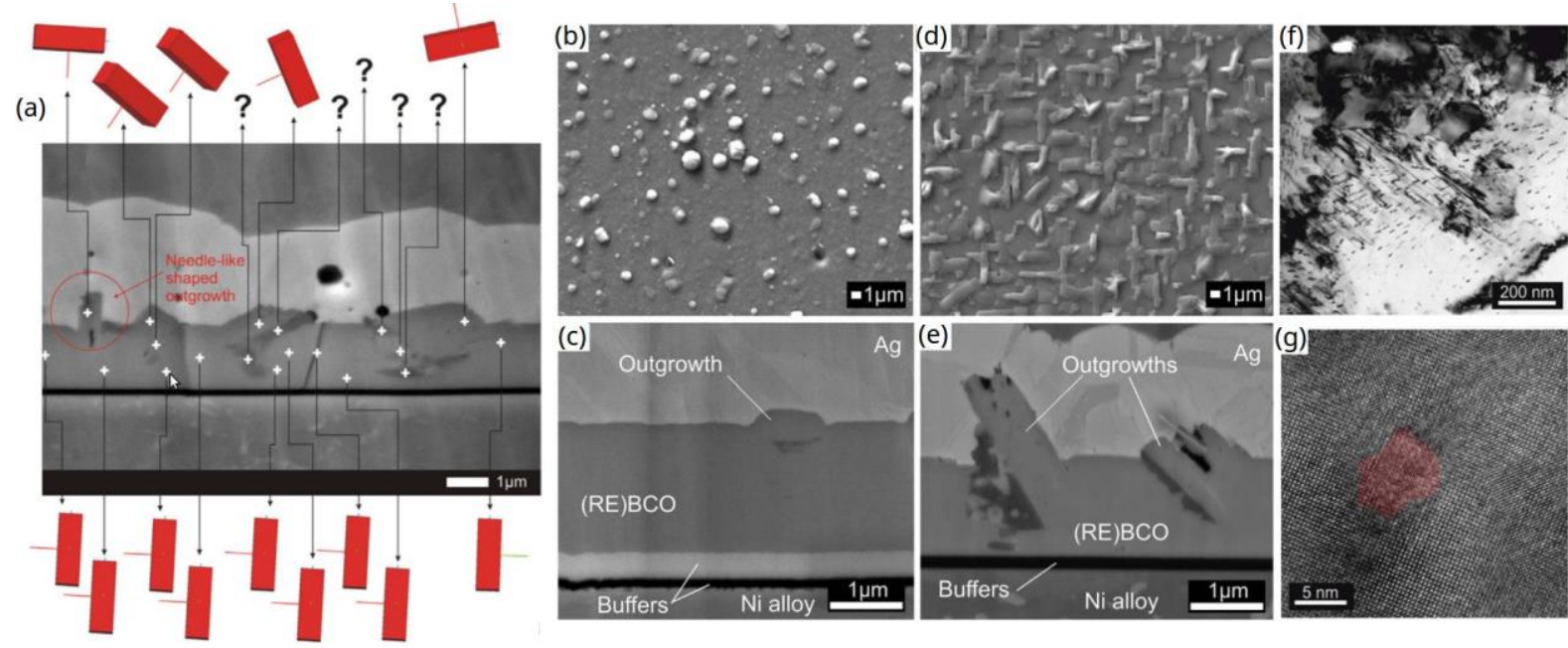

Fig. 3 Structural features of a superconductor before mechanical loading. (a) SEM images of crosssection of SCS4050 tape (3). At white crosses the crystal orientation of (RE)BCO was attempted to identify by EBSD. (b) Rounded outgrowths (top view) with corresponding cross-section (c). Needlelike outgrowths $(d)$ with a corresponding cross-section (e). Top views by TEM (f) (4), with detail on

$\mathrm{BaZrO}_{3}$ artificial pinning centre $(\mathrm{g})$

Apart from the mentioned undesired inhomogeneities with dimensions in the order of $10^{-6}$ $\mathrm{m}$ (Figs. 3b-e, SEM), smaller particles can be often found in the structure. The nanoparticles artificially introduced to the superconductive layer enhance the pinning of magnetic vortices (4). The nanocolumns with dimensions in the order of $10^{-8} \mathrm{~m}$ can be seen in Fig. $3 \mathrm{f}$, with the detail of crystalline structure of one such nanoparticle (Fig. 3g). Investigation of the (rather unintuitive) intentional imperfectioning of the structure can also help to improve the properties of superconducting tapes, e.g. better performance in higher magnetic fields.

Effect of deposition temperature on the HTS layer structure was investigated on selfprepared films with artificial pinning by the MOCVD, RCE and PLD techniques; the most satisfying results were provided by the latter technique (10).

\section{Structure of mechanically loaded superconducting layer: experiments and modelling}

The main drawback of the ceramic nature of HTS, especially in thin layers, is its sensitivity to mechanical loads. In general, attention is paid to minimizing the loading, but it cannot be completely avoided, e.g. during cabling of single tapes into cables (Fig. 4a), or when the cables are bent (Fig. 4b). Hence, limits of the maximal load must be determined in order to avoid significant degradation the electromagnetic properties of tapes $(5,9)$. 

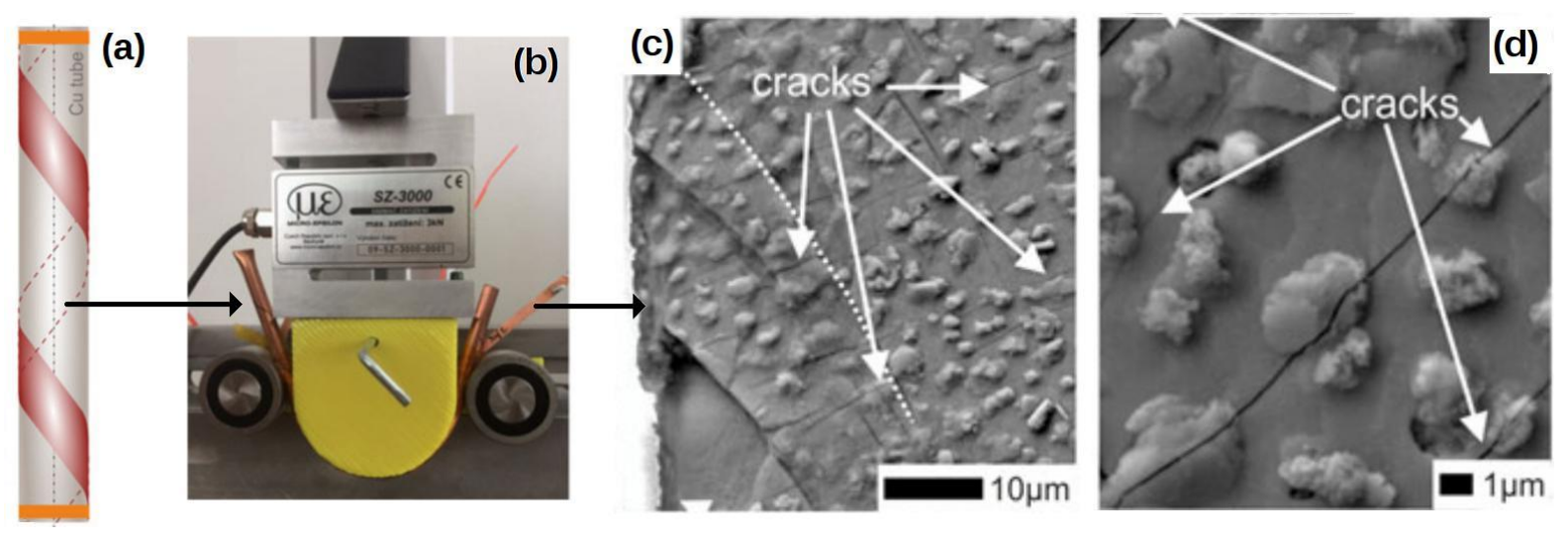

Fig. 4 Examination of degradation during cabling (5). (a) To ensure cooling during operation, HTS tapes (red, only one tape shown) are cabled onto a round hollow tube (grey). (b) Setup for bending tests at room temperature. (c) Damaged HTS layer after winding onto Cu tube with diameter of 3.2 mm imaged by SEM: delamination occurred at the left bottom corner and (d) crack propagation was not stopped at outgrowths.

Two cable helix arrangements were researched: the "out" type (Figs. $4 \mathrm{c}$ and d), where the tapes were wound oriented with the (RE)BCO layer outward from the tube, and the "in" type, with reversed orientation. Strong dependence of critical current degradation was observed on the helix arrangement. Since more advantageous compressive stresses are acting on HTS in the "in" type cabled tapes during loading, this arrangement allows winding the tapes on tubes with diameter down to $4.15 \mathrm{~mm}$ without significant degradation of their critical current.
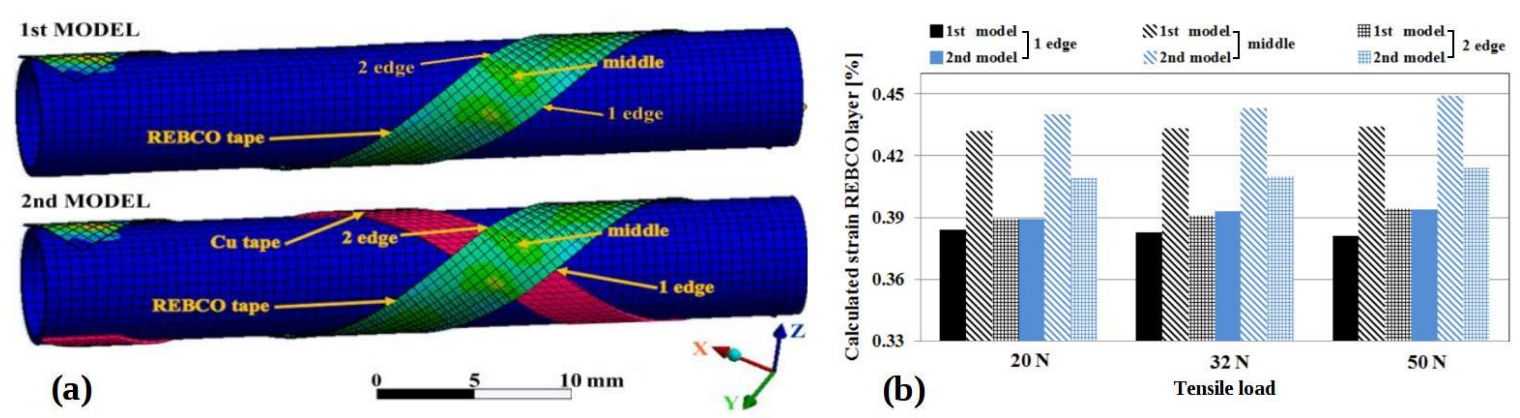

Fig. 5 (a) Schematic of two FEM models for combined tension-winding of HTS tapes (6): tape on bare $\mathrm{Cu}$ tube (1st model) and tape on tube with wound Cu tape as the inner layer (2nd model).

(b) Comparison of the distribution of transverse strain in the HTS tape wound under the winding angle of $37^{\circ}$ and various tensile loads, using the two models (6).

Along with the experiments, a detailed structural finite-element (FE) analysis using the FE ANSYS code was carried out to investigate the stress-strain behaviour and to predict the critical loads of $\mathrm{CC}$ tapes under tension and bending loading during the winding process $(6,11)$. Within the 1st model (Fig. 5a top), we can consider all winding parameters investigated as safe before any operational stresses are applied. On the other hand, in the 2nd model (Fig. 5a bottom) we observed an overrun of intrinsic strain at $37^{\circ}$ and $50 \mathrm{~N}$ tensile force. Fig. $5 \mathrm{~b}$ shows that the highest values of strain in (RE)BCO layer are generated in the middle part of the tape (along the tape width). From variation in thicknesses of particular layers we concluded that the tapes with thinner substrate and thicker $\mathrm{Cu}$ overlayer are more favorable for winding on round tube. 


\section{Soldered joints of superconducting tapes}

Although preparation of superconducting joints with direct contact of the two connecting superconducting layers has been reported by other workgroups, fabrication of such joints remains tedious and costly. On the other hand, the use of traditional lead solders of well- known properties is on decline for ecological reasons; we therefore tested the use of lead-free solders in preparation of easily made joints between two facing tapes (Fig. 6a) (7).

(a)

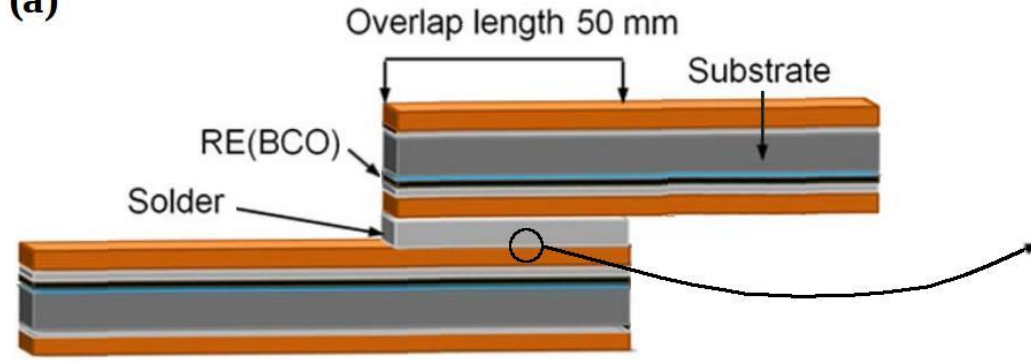

(b)

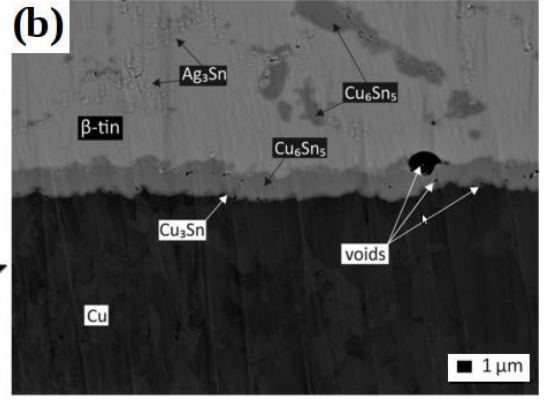

Fig. 6 (a) Cross-section scheme of overlap soldered joint configuration (SuperPower SCS12050); thicknesses of particular layers are not in scale (7). (b) Phases in the interface between the Cu layer of the tape and the solder (EDX) (7)

Investigations were focused on the most important characteristics of the joint - its resistivity $R$. Unexpectedly, thermal cycling of the soldered joint caused slight reduction of $R$. Use of flux seemed to play an important role in soldering process, and we found dependence of $R$ on the duration of reflow time during soldering. We also discussed correlation between the joint microstructure (Fig. 6b) and its properties. A study about testing the effects of various chemical compositions of solders was also conducted (8).

\section{CONCLUSION}

We presented a review of major achievements of the research team investigating superconductors. The review was mostly based on our most important Current Contents publications (1-8), which earned so far more than 45 citations (Web of Science, November 2018). Since the award of the first research grant to our group in 2011, we have been involved in three domestic research projects (VEGA, APVV) and one international project ("FASTGRID", item 4 in Acknowledgements). We also paid attention to dissemination of our work in popularization articles (12-14) and conference contributions and abstracts (15-24). In total, 20 students received their degree in the field of superconductors, of which eight earned their bachelor degrees, 10 master degrees, and two doctoral degrees.

In the near future, our team plans to initiate new domestic research projects and to intensify international collaboration aimed at improving the performance of coated conductors in applications.

\section{Acknowledgements}

Although this review was limited only to structural analysis of superconductors, our research would be incomplete without electromagnetic characterisations made by our main partner - the Department of Superconductors at the Institute of Electrical Engineering, Slovak Academy of Sciences. 
This research was supported by (1) the Slovak Research and Development Agency under the Contract No. APVV-14-0438; (2) VEGA grant agency under the Contracts Nos. 1/0162/11 and 1/0151/17; (3) the European Commission EURATOM project FU07-CT-2007-00051 cofunded by the Slovak Research and Development Agency under the Contract No. DO7RP0018-12; (4) European Union's Horizon 2020 research and innovation programme under the grant agreement No. 721019; (5) the domestic project "Projekt Podpora mladých výskumníkov" under the Contract 1339; (6) the Research and Development Operational Programme funded by the ERDF through the projects of 'Centre for development and application of advanced diagnostic methods in the processing of metallic and non-metallic materials', ITMS: 26220120014 and 'CE for development and application of advanced diagnostic methods in the processing of metallic and non-metallic materials - APRODIMET', ITMS: 26220120048; (7) the Structural Funds of the European Union through the Agency of the Ministry of Education, Science, Research, and Sports of the Slovak Republic through the Project of "CENTE II" (ITMS: 26240120011).

\section{References:}

1. GÖMÖRY, F. et al. 2013. AC Loss in Pancake Coil Made From $12 \mathrm{~mm}$ Wide REBCO Tape. In IEEE Transactions on Applied Superconductivity, 23(3), pp. 6. ISSN 1051-8223.

2. SOLOVYOV, M. et al. 2013. Non-uniformity of coated conductor tapes. In Superconductor Science and Technology, 26(11), Art.No. 115013. ISSN 0953-2048.

3. PEKARČÍKOVÁ, M. et al. 2014. Investigation of defects in functional layer of high temperature superconducting tapes. In Physica C-Superconductivity and its Applications, Vol. 497, pp. 24-29. ISSN 0921-4534.

4. MIŠÍK, J. et al. 2016. Structural study of commercially produced (RE)BCO films. In IEEE Transactions on Applied Superconductivity, 26(3), pp. 804-804. ISSN 1051-8223. DOI: 10.1109/TASC.2016.2516348.

5. PEKARČÍKOVÁ, M. et al. 2018. Effect of Mechanical Loading on Coated Conductor Tapes Due to Winding Onto Round Cables. In IEEE Transactions on Applied Superconductivity, 28(4), pp. 505-505. ISSN 1051-8223. DOI: 10.1109/TASC.2018.2795894.

6. MICHALCOVÁ, E. et al. 2018. Structural modeling of REBCO coated conductor tapes in TORT cables. In IEEE Transactions on Applied Superconductivity, 28(4), pp. 5. ISSN 1051-8223.

7. MICHALCOVÁ, E. et al. 2016. Joining of CC Tapes With Lead-Free Solders. In IEEE Transactions on Applied Superconductivity, 26(3), Article 8801104. ISSN 1051-8223. DOI: 10.1109/TASC.2016.2539419.

8. DRIENOVSKÝ, M. et al. 2018. Induction Soldering of Coated Conductor High-Temperature Superconducting Tapes With Lead-Free Solder Alloys. In IEEE Transactions On Applied Superconductivity, 28(4), 6601305.

9. KONOPKA, P. 2014. Characterization of defects in the structure of non-metallic superconductors. Trnava: MTF STU. 104 pp. Dissertation thesis.

10. MIŠÍK, J. 2017. Characterization of fine structure of superconducting layers in high temperature superconducting tapes. Trnava: MTF STU, 93 p. Dissertation thesis.

11. CUNINKOVÁ*, E. 2019. Degradation of superconducting tapes by mechanical stress. Trnava: MTF STU. Dissertation thesis (in preparation for defense in 2019). *maiden name MICHALCOVÁ

12. SKARBA, M. et al. 2014. Mirko v mikrosvete materiálov: vedecká sci-fi rozprávka (Mirko in the micro-world of materials: a sci-fi tale). In Quark, 2, pp. 19-23.

13. SKARBA, M. et al. 2016. Supravodivé materiály a ich využitie (Superconductive materials and their application). In Quark, 11, pp. 7-11.

14. SKARBA, M. et al. 2017. Levitujúci vlak a smotanová zmrzlina (A levitating train and ice-cream). In Quark, 8, pp. 54. 
15. KONOPKA, P. et al. 2012. Sample preparation from high temperature superconducting tapes. In International Doctoral Seminar 2012: Proceedings. Smolenice Castle, SR, May 20-22, 2012. Trnava: AlumniPress, pp. 218-227. ISBN 978-80-8096-164-0.

16. KONOPKA, P. et al. 2013. Inhomogeneities in the structure of high temperature superconducting layer. In IDS 2013. International Doctoral Seminar 2013 (electronic source): Proceedings of the 8th International Doctoral Seminar (IDS 2013), Dubrovnik, 13-15 May 2013. Zagreb: University of Zagreb, pp. 159-165. CD-ROM. ISBN 978-953-6071-40-1.

17. KONOPKA, P. et al. 2013. Investigation of mechanical properties of (RE)BCO base coated conductors. In EUCAS 2013: 11th European Conference on Applied Superconductivity. Italy, Genova. September 15-19, 2013. Abstract Book: European Society for Applied Superconductivity, pp. 382.

18. PEKARČÍKOVÁ, M. et al. 2013. Study of crystal orientation in (RE)BCO-based HTS tapes. In EUCAS 2013: 11th European Conference on Applied Superconductivity. Italy, Genoa. September 15-19, 2013. Abstract Book: European Society for Applied Superconductivity, pp. 378.

19. SKARBA, M. et al. 2013. Structural inhomogeneities in (RE)BCO layer. In EUCAS 2013: 11th European Conference on Applied Superconductivity. Italy, Genova. September 15-19, 2013. Abstract Book: European Society for Applied Superconductivity, pp. 371.

20. CUNINKOVÁ*, E. et al. 2018. Overlap joints of CC tapes tested by thermal cycling and mechanical load. In Coated Conductors for Applications. CCA 2018 (electronic source): Workshop, September 10-13, 2018. Vienna, 1st Issue, pp. 31.

21. MICHALCOVÁ, E et al. 2017. Structural modelling of REBCO CC tapes in TORT cables. In EUCAS 2017 (electronic source): 13th European Conference on Applied Superconductivity. Geneva, 17 - 21 September 2017. 1st Iss. [online]. Geneva: European Society for Applied Superconductivity.

22. PEKARČÍIKOVÁ, M. et al. 2017. Effect of mechanical loading on high temperature superconducting tapes during bending of round cables. In EUCAS 2017 (electronic source): 13th European Conference on Applied Superconductivity. Geneva, 17 - 21 September 2017. 1st Iss. [online]. Geneva: European Society for Applied Superconductivity, 2017.

23. PEKARČÍKOVÁ, M. et al. 2018. Investigation of CC tapes with soldered metallic high heat capacity layer suitable for superconducting fault current limiters. In Coated Conductors for Applications. CCA 2018 (electronic source): Workshop 2018. September 10-13, 2018. Vienna, 1st Issue, p. 80.

24. ŠOUC, J. et al. 2018. CORC® cable production and its use in the coil winding. In Coated Conductors for Applications. CCA 2018 (electronic source): Workshop 2018. September 10-13, 2018. Vienna, 1st Issue, pp. 16.

\section{ORCID:}

Marcela Pekarčíková

0000-0002-4300-6109 